\title{
Effect of hydrofluoric acid surface treatments on micro-shear bond strength of CAD/CAM ceramics
}

\author{
Faraneh Mokhtarpour ${ }^{1}$, Homayoon Alaghehmand ${ }^{2}$, Soraya Khafri ${ }^{3}$
}

${ }^{1}$ Assistant Professor, Department of Esthetic and Restorative Dentistry, Babol University of Medical Sciences, Babol, Iran

${ }^{2}$ Associate Professor, Dental Materials Research Center, Department of Esthetic and Restorative Dentistry, Babol University of Medical Sciences, Babol, Iran

${ }^{3}$ Ph.D. of Biostatistics, Assistant Professor, Department of Biostatistics and Epidemiology, Faculty member of Biostatistics Sciences, Babol University of Medical Sciences, Babol, Iran

\section{Type of article: Original}

\begin{abstract}
Introduction: Dental ceramics are appreciated as highly esthetic restorative materials that can simulate the appearance of natural dentition better than other materials. The aim of this study was to evaluate the effect of hydrofluoric acid concentration and etching time on micro-shear bond strength ( $\mu$ SBS) to IPS e.max CAD and Vita Mark II of a dual cured resin cement (Panavia F2.0).

Methods: This study was an experimental in vitro study, performed in the dental material research center of Babol University of Medical Sciences in 2016. Two hydrofluoric acid concentrations (5\% and 10\%) and three different etching times (20,60 and 120 seconds) were used to etch the specimens respectively. A silane coupling agent (Clearfil porcelain activator) and priming and bonding agent (Clearfil SE bond) were used on the etched surfaces in accordance to the manufacturer's instructions of use. Then resin cement was applied on the prepared ceramic surfaces and light cured. $\mu$ SBS between resin cement and the porcelains were measured with a universal testing machine. Mode of failure was observed with 40x magnification by means of a Stereo microscope. Data were analyzed with ANOVA and independent-samples t-test and Chi-square tests.

Results: In both e.max and Vita Mark II groups, $\mu$ SBS were not significantly different when different etching times (one-way ANOVA) and HF acid concentrations (Independent-samples t-test) were used ( $>0.05$ ), but the highest $\mu$ SBS was shown in e.max specimens etched $60 \mathrm{~s}$ with $5 \%$ HF and Vita Mark II specimens etched $20 \mathrm{~s}$ with $10 \%$ HF. $\mu$ SBS of e.max was significantly higher than Vita Mark II $(p=0.00)$.

Conclusion: Best surface treatment for e.max and Vita Mark II ceramics is $20 \mathrm{~s}$ etch using $5 \%$ hydrofluoric acid. Keywords: Glass ceramic; Hydrofluoric acid; Resin cement; CAD/CAM; Adhesion
\end{abstract}

\section{Introduction}

Dental ceramics are appreciated as highly esthetic restorative materials that can simulate the appearance of natural dentition better than other materials (1). The use of all ceramic prosthesis in restorative treatments has become popular, and many of these restorations can be fabricated by both traditional laboratory methods and computer aided design/computer aided manufacturing $(\mathrm{CAD} / \mathrm{CAM})$ machination. The traditional methods of ceramic fabrication have been described to be time-consuming, technique sensitive and unpredictable due to the many variables and $\mathrm{CAD} / \mathrm{CAM}$ may be a good alternative for both the dentists and laboratories (2). CAD/CAM may also reduce the fabrication time of high strength ceramics by up to $90 \%$. Furthermore, industrially fabricated blocks are more homogenous with minimal flaws (3). Lithium disilicate and feldspathic ceramic are silica-based ceramics. Feldspathic porcelain is a composite of leucite (potassium aluminosilicate) and glass and lithium disilicate ceramics comprised of approximately $65 \%$ volume of highly interlocking lithium disilicate crystals discharged in a glassy

\section{Corresponding author:}

Associate Professor Dr. Homayoon Alaghehmand, Dental Materials Researches Center, Department of Esthetic and Restorative Dentistry, Babol University of Medical Sciences, Babol, Iran.

Tel: +98.9111140482, Email: halagheh@yahoo.com

Received: June 26, 2016, Accepted: July 26, 2016, Published: October 2017

iThenticate screening: July 26, 2016, English editing: August 02, 2017, Quality control: August 14, 2017

(C) 2017 The Authors. This is an open access article under the terms of the Creative Commons Attribution-NonCommercialNoDerivs License, which permits use and distribution in any medium, provided the original work is properly cited, the use is non-commercial and no modifications or adaptations are made. 
matrix (4). Vita Mark II is CAD/CAM feldspathic ceramic that was introduced for the CEREC system in 1991 (5). IPSTM E.max CAD (Ivoclar Vivadent) is lithium disilicate ceramic that was introduced in 2006 for chairside use (3, 6). For survival of the porcelain laminate veneers in the oral environment, bonding achieved between the porcelain and resin cement is essential $(7,8)$. Modification of the internal porcelain surfaces by acid etching or air abrasion, resulted in improved bonding $(9,10)$. A well-known method for increasing bond strength is etching the ceramic surfaces with hydrofluoric acid and then applying a silane coupling agent on the etched surfaces (11). A routine surface pre-treatment for the restoration with dental porcelains is the combination of appropriate etching process following by the application of silane coupling agent (12). Hydrofluoric acid etching on porcelain structures leads to increased surface roughness and higher surface energy (13). Surface modification of the porcelain increases the surface area available for bonding and creates undercuts that increase the bond strength to the resin cement. Subsequent examination of the etched porcelain surfaces, showed that different processes of etching of porcelain surfaces dissolved different porcelain phases preferentially depending on the porcelain composition, and created a more conductive surface for bonding $(14,15)$. There is a reaction between the Hydrofluoric acid and the silica containing glass matrix and that forms hexafluorosilicates. Following removal of the glass matrix, the crystalline structure is exposed resulting in the surface of the ceramic becoming rough, which is required for micromechanical retention (16-18). Its rough surface also provides more surface energy prior to incorporating the silane solution (17, 19). Several different etching periods have been suggested and used since the introduction of HF acid etching as a ceramic surface pretreatment for resin bonding, (1). It was found that increasing etching duration time (HF) resulted in higher shear bond strength between resin adhesive and dental CAD/CAM porcelain within a range of 0 to $120 \mathrm{~s}$ (18). The manufacturer's Advocated etching time for cementation of the IPS e.max Press glass ceramic restorations with a resin cement is about 20 s. J.H Chen in 1998, recommended 120 s etching time with $5 \%$ HF acid for Vita Mark II to obtain highest bond strength (18). However, clinically, the optimal HF acid etching time and concentration to treat the glass ceramic restoration surface is not clear and there are not enough articles about appropriate etching time for $\mathrm{CAD} / \mathrm{CAM}$ ceramics. Therefore, it is important to know the adequate and optimal HF etching time for resin cement bonding without weakening the ceramic (1). Null hypotheses of this study were: 1) Micro-shear bond strength of resin cement with resin cement increase with increasing etching time, 2) Micro-shear bond strength of resin cement with resin cement increase with increasing HF concentration.

\section{Material and Methods}

\subsection{Research design}

This study was an experimental in vitro study, which was conducted at the dental material research center of Babol University of Medical Sciences in 2016.

\subsection{Specimen preparation}

Two types of CAD/CAM chairside ceramics were used in this survey, Feldspathic (Vita Mark II (M)) and Lithium disilicate (IPs e.maxTM CAD(E)) (Table 1). Six blocks No.14 of each ceramic were used. Each block sectioned in width to five pieces using a water-cooled diamond disk with a low-speed saw machine (Delta precision sectioning machine, Mashhad, Iran). For creating a standard surface, blue diamond bur was used for grounding the ceramic surface. Then all specimens were finished to 600 grit silicon carbide paper to simulate CAD/CAM milled surfaces. e.max specimens were heated under vacuum in an oven in order to complete their crystallization. Two different concentrations of handmade HF acid, $5 \%$ (a) and 10\% (b) (Table 1), were used to etch ceramics. Three etching times were evaluated in this study: $20 \mathrm{~s}, 60 \mathrm{~s}$ and $120 \mathrm{~s}$. Therefore, we had six subgroups for each ceramic (30 pieces): Ma20, Ma60, Ma120, Mb 20, Mb60, Mb120 (Vita Mark II subgroups) and Ea20, Ea60, Ea120, Eb20, Eb60, Eb120 (e.max subgroups). After etching specimens according to their subgroup etching time, they were rinsed with airwater spray for 30 seconds. Then they were ultrasonically cleaned in distilled water for five minutes. For removing any contamination from the ceramic's surface, we used phosphoric etchant gel (Table 1) for five seconds on the pieces and then they were washed and air dried and placed in $99 \%$ alcohol, then dried with compressed hot air.

\subsection{Bonding method}

Thirty pieces for each ceramic were used. The ceramic pieces were equally and randomly assigned to six study groups and etched according to their subgroup. One layer of equal mix of silane coupling agent and clearfil SE bond primer was applied onto all ceramic pieces and allowed to be air dried for 60 seconds. Then one layer of clearfil SE bond was applied onto the ceramics. After that, an equal amount of paste A and B of Panavia (Table 1) were mixed for more than 20 seconds and applied onto the prepared ceramics. Cement interfaces were cured for 20 second from each side with VALO LED (Ultradent USA) with $1000 \mathrm{mw} / \mathrm{cm} 2$ intensity. 


\subsection{Micro-shear bond strength test}

Ultimately, the pieces were sectioned perpendicular to the bonding interface area to obtain beams with a bonding area of about $1 \mathrm{~mm} 2$ using a water-cooled diamond disk in a sectioning machine (Delta precision sectioning machine, Mashhad, Iran). Two beams from each piece were obtained. So, 10 beams in each experimental group were tested for $\mu$ SBS (60 total beams for $\mu$ SBS test). The cross-sectional area of each beam was measured using a digital caliper (Shinwa Rules Co., Niigata, Japan). Micro-shear bond strengths were measured with Zwick Universal Testing machine (Zwick GmbH \& Co., Ulm, Germany) at a crosshead speed of $0.5 \mathrm{~mm} / \mathrm{min}$ until failure. The resultant forces in $\mathrm{N}$ were divided into the cross-sectional area and the pressures in Mpa were calculated.

\subsection{Failure mode}

Failure mode of beams were evaluated with a stereomicroscope with 40X magnification and reported into three groups: 1) Failure in ceramic or resin cement (cohesive); 2) Failure in the interface of ceramic and resin cement (adhesive); and 3) Failure in ceramic or resin cement and the interface (mixed).

\subsection{Statistical analysis}

Independent-samples t-test was used for $\mu \mathrm{SBS}$ and Ra comparison between different HF concentrations and type of ceramic. One-way ANOVA was used for comparison between different etching times. Two-way and three-way ANOVA was used for evaluating interactions among the factors. Chi-square test was used for analysis of mode of failure.

Table 1. Material descriptions, manufacturers, compositions and batch number

\begin{tabular}{|c|c|c|}
\hline $\begin{array}{l}\text { Material } \\
\text { (manufacturer) }\end{array}$ & Description & Composition and batch number \\
\hline $\begin{array}{l}\text { Panavia F2.0: Kuraray } \\
\text { Medical Inc, Osaka, } \\
\text { Japan }\end{array}$ & $\begin{array}{l}\text { Dual-cure } \\
\text { single-step } \\
\text { self-etch } \\
\text { resin cement }\end{array}$ & $\begin{array}{l}\text { ED Primer II; Liquid A: HEMA (30\%-50\%), MDP, Nmethacryloyl-5- } \\
\text { aminosalicylic acid, water, accelerator } \\
\text { (61185); ED primer II liquid B: N-methacryloyl-5- aminosalicylic acid, } \\
\text { accelerator, water, sodium benzene sulfinate ( } 61185) \text {; Paste A: hydrophobic } \\
\text { aromatic and aliphatic dimethacrylate, hydrophilic aliphatic dimethacrylate, } \\
\text { sodium aromatic sulfinate (TPBSS), N,N diethanol-p-toluidine, surface- } \\
\text { treated (functionalized) sodium fluoride ,10\%, silanated barium glass } \\
\text { (61185); Paste B: MDP, hydrophobic aromatic and aliphatic dimethacrylate, } \\
\text { hydrophilic aliphatic dimethacrylate, silanated silica, photo initiator, } \\
\text { dibenzoyl peroxide (61185) }\end{array}$ \\
\hline $\begin{array}{l}\text { Clearfil SE Bond: } \\
\text { Kuraray Medical } \\
\text { Inc, Osaka, Japan }\end{array}$ & $\begin{array}{l}\text { Light-cure self- } \\
\text { etch adhesive }\end{array}$ & $\begin{array}{l}\text { Primer: MDP, HEMA, Hydrophilic dimethacrylate, N, N-Diethanol, p- } \\
\text { toluidine, water(00109A) Bonding: MDP, Bis-GMA, HEMA hydrophobic } \\
\text { dimethacrylate, dl-Campherquinone, N, N-Diethanol p-toluidine, silanated } \\
\text { silicate(00043A) }\end{array}$ \\
\hline $\begin{array}{l}\text { Clearfil Porcelain } \\
\text { Bond Activator: } \\
\text { Kuraray Medical Inc, } \\
\text { Osaka, Japan }\end{array}$ & $\begin{array}{l}\text { One bottle pre- } \\
\text { activated silane }\end{array}$ & $\begin{array}{l}\text { Bisphenol A polyethoxy dimethacrylate, } 3 \text { methacryloyl oxypropyl } \\
\text { trimethoxy silane (00241A) }\end{array}$ \\
\hline $\begin{array}{l}\text { VITA BLOCS Mark } \\
\text { II: VITA Zahnfabrik, } \\
\text { Bad Säckingen, } \\
\text { Germany }\end{array}$ & $\begin{array}{l}\text { CEREC/in Lab } \\
(2 \mathrm{M} 1 \mathrm{C} \text { I12) } \\
\text { block }\end{array}$ & $\begin{array}{l}\text { Mixture of feldspathic crystalline particles embedded in a glassy matrix Vol } \\
\% \approx 30(15670)\end{array}$ \\
\hline $\begin{array}{l}\text { IPS e.max CAD } \\
\text { blocks: Ivoclar } \\
\text { Vivadent, } \\
\text { Liechtenstein }\end{array}$ & $\begin{array}{l}\text { Lithium } \\
\text { disilicate } \\
\text { blocks }\end{array}$ & $\begin{array}{l}\mathrm{SiO}_{2}(57-80 \%), \mathrm{Li}_{2} \mathrm{O}(11-19 \%), \mathrm{K}_{2} \mathrm{O}(0-13 \%), \mathrm{P}_{2} \mathrm{O}_{5}(0-11 \%), \mathrm{ZrO}_{2}(0- \\
\left.8 \%), \mathrm{Al}_{2} \mathrm{O}_{3}(0-5 \%), \mathrm{MgO} 90-5 \%\right) \text { and coloring oxides }(0-8 \%)\left(\mathrm{R}_{4} 456\right)\end{array}$ \\
\hline $\begin{array}{l}\text { Merk Hydrofluoric } \\
\text { acid } 40 \% \text { : } \\
\text { Merk, Darmstadt. } \\
\text { Germany }\end{array}$ & $\begin{array}{l}\text { Liquid } 40 \% \\
\text { hydrofluoric } \\
\text { acid }\end{array}$ & $\begin{array}{l}\text { Chloride:1ppm, Hexafluorosilicate }: 50 \text { ppm, phosphate:0.5 ppm, Sulphate:2 } \\
\text { ppm, Arsenic \& Antimony:0.03 ppm, Silver:0.020 ppm, Aluminium:0.050 } \\
\text { ppm, Barium:0.050 ppm, Beryllium:0.020 ppm, Bismuth:0.020 ppm, } \\
\text { Calcium:0.200 ppm (B0710538231) }\end{array}$ \\
\hline $\begin{array}{l}\text { Scotchbond Etchant } \\
\text { gel: } 3 \mathrm{M} \text { ESPE, St. } \\
\text { Paul, MN, USA }\end{array}$ & $\begin{array}{l}35 \% \text { acid } \\
\text { phosphoric } \\
\text { etchant gel }\end{array}$ & $\begin{array}{l}35 \% \text { by weight Phosphoric acid, } 60 \% \text { water and 5\% Synthetic amorphous } \\
\text { silica as thickening agent(N105148) }\end{array}$ \\
\hline
\end{tabular}




\section{Results}

\subsection{Micro-shear bond strength}

Mean $\mu$ SBS and standard deviation of the e.max and Vita Mark II are shown in Table 2. In both e.max and Vita Mark II groups, $\mu$ SBS were not significantly different when different etching times (one-way ANOVA) and HF acid concentrations (Independent-samples t-test) were used ( $p>0.05$ ), but the highest $\mu$ SBS was shown in Ea60 and Mb20 groups. The $\mu$ SBS of e.max was significantly higher than Vita Mark II ( $p=0.00$, one-way ANOVA). The $\mu$ SBS was not significantly different between etching times and HF acid concentrations in Vita Mark II. Statistical analysis showed that $\mu$ SBS did not have significant difference between different concentrations, times and ceramics (three-way ANOVA).

\subsection{Mode of failure}

Modes of failure are shown in Table 3. Chi-square test showed for e.max groups that in 20,60 and $120 \mathrm{~s}$ etching times, HF concentration did not have any significant influence on failure mode. Without considering etching times, $\mathrm{HF}$ concentration had significant effect on failure mode. In 5\% concentration, adhesive failure was more than others and in $10 \%$ concentration, mixed failure was dominant. In Vita Mark II groups, only in $60 \mathrm{~s}$ etching time, HF concentration had significant influence on failure mode, and cohesive failure was the most in 5\% concentration, and in $10 \%$ concentration adhesive failure was the most. Without considering etching times, HF concentration had significant effect on failure mode, so in $5 \%$ concentration cohesive failure was the most and in $10 \%$ concentration adhesive failure was dominant.

Table 2. Micro-shear bond strength (MPa) of e.max \& Vita Mark II

\begin{tabular}{|l|l|l|}
\hline \multirow{2}{*}{ e.max } \\
\hline \multirow{2}{*}{ Acid time } & \multicolumn{2}{|l|}{ Acid concentration } \\
\cline { 2 - 3 } & $5 \%$ & $10 \%$ \\
\hline $20 \mathrm{~s}$ & $10.52 \pm 5.39^{\mathrm{aA}}$ & $13.59 \pm 6.93^{\mathrm{aA}}$ \\
\hline $60 \mathrm{~s}$ & $16.84 \pm 9.85^{\mathrm{aA}}$ & $14.35 \pm 7.02^{\mathrm{aA}}$ \\
\hline $120 \mathrm{~s}$ & $12.76 \pm 4.56^{\mathrm{aA}}$ & $14.94 \pm 4.13^{\mathrm{aA}}$ \\
\hline Vita Mark II \\
\hline \multirow{2}{*}{ Acid time } & Acid concentration \\
\cline { 2 - 3 } & $5 \%$ & $10 \%$ \\
\hline $20 \mathrm{~s}$ & $6.32 \pm 2.92^{\mathrm{aA}}$ & $7.18 \pm 2.97^{\mathrm{aA}}$ \\
\hline $60 \mathrm{~s}$ & $5.96 \pm 3.66^{\mathrm{aA}}$ & $5.21 \pm 1.04^{\mathrm{aA}}$ \\
\hline $120 \mathrm{~s}$ & $6.88 \pm 2.64^{\mathrm{aA}}$ & $5.95 \pm 2.4^{\mathrm{aA}}$ \\
\hline
\end{tabular}

The different lowercase letters indicate a significant difference $(\mathrm{p}=0.05)$ between the etching times maintaining the same acid concentration. Different capital letters indicate a significant difference $(\mathrm{p}=0.05)$ between Acid concentration maintaining the same time.

Table 3. Mode of failure

\begin{tabular}{|c|c|c|c|c|c|}
\hline Ceramic & HF concentration & Etching time & Adhesive failure & Cohesive failure & Mixed failure \\
\hline \multirow{6}{*}{ e.max } & \multirow{3}{*}{$5 \%$} & $20 \mathrm{~s}$ & $7(70 \%)$ & $1(10 \%)$ & $2(20 \%)$ \\
\hline & & $60 \mathrm{~s}$ & $3(30 \%)$ & $4(40 \%)$ & $3(30 \%)$ \\
\hline & & $120 \mathrm{~s}$ & $3(30 \%)$ & $6(60 \%)$ & $1(10 \%)$ \\
\hline & \multirow[t]{3}{*}{$10 \%$} & $20 \mathrm{~s}$ & $3(30 \%)$ & $2(20 \%)$ & $5(50 \%)$ \\
\hline & & $60 \mathrm{~s}$ & $2(20 \%)$ & $1(10 \%)$ & $7(70 \%)$ \\
\hline & & $120 \mathrm{~s}$ & $1(10 \%)$ & $4(40 \%)$ & $5(50 \%)$ \\
\hline \multirow[t]{6}{*}{ Vita Mark II } & \multirow[t]{3}{*}{$5 \%$} & $20 \mathrm{~s}$ & $4(40 \%)$ & $4(40 \%)$ & $2(20 \%)$ \\
\hline & & $60 \mathrm{~s}$ & $2(20 \%)$ & $5(50 \%)$ & $3(30 \%)$ \\
\hline & & $120 \mathrm{~s}$ & $2(20 \%)$ & $5(50 \%)$ & $3(30 \%)$ \\
\hline & \multirow[t]{3}{*}{$10 \%$} & $20 \mathrm{~s}$ & $6(60 \%)$ & $3(30 \%)$ & $1(10 \%)$ \\
\hline & & $60 \mathrm{~s}$ & $8(80 \%)$ & $2(20 \%)$ & $0(0 \%)$ \\
\hline & & $120 \mathrm{~s}$ & $4(40 \%)$ & $4(40 \%)$ & $2(20 \%)$ \\
\hline
\end{tabular}

\section{Discussion}

In this study, Micro-shear testing results showed that there is no significant difference between different acid concentrations and etching times for each porcelain, so number 1 and 2 null hypotheses were rejected. According to 
this study, best surface treatment for e.max and Vita Mark II ceramics is $20 \mathrm{~s}$ etch using $5 \%$ hydrofluoric acid. Both chemical and mechanical retention are necessary for a reliable bonding between ceramics and resin cement. Porcelain surface treatments increasing the micromechanical retention of the resin cement by modifying its texture. Silane coupling agents react with the glassy matrix of the ceramic and with the composite organic matrix, so they lead to chemical retention between ceramic and resin cement $(20,21)$. For these reasons, we used HF acid and silane coupling agent for treating ceramic surfaces. Since the concept of etching porcelain surface was introduced and adhesive cementation of porcelain laminate veneers was reported, many authors have stated that the concentrations and etching periods must be adjusted to each type of ceramic in order to optimize the bond strength $(14,16,18,21$ 23). To avoid reducing the strength of the ceramic, it is important to know the optimal HF etching time for micromechanical retention (17). For this reason, research on the adequate etching protocol for a lithium disilicatebased and feldspathic glass ceramic was carried out in the present study. Regarding etching time, a number of studies have been carried out using various types of ceramic and HF etchants $(16-18,24,25)$. Chen et al. (16) evaluated two HF etchants $(2.5$ and $5 \%)$ and seven different etching times $(0,30,60,90,120,150$, and $180 \mathrm{~s})$ for feldspathic porcelain treatment. They determined that etching periods of more than $30 \mathrm{~s}$ increased the bond strength to resin and that $2.5 \% \mathrm{HF}$ yielded higher bond strengths to resin than the 5\% HF for all etching time periods, except $180 \mathrm{~s}$. A study by Guler et al. (24) evaluated the effect of a number of $9.6 \% \mathrm{HF}$ etching times $(30 \mathrm{~s}, 30+30 \mathrm{~s}, 60 \mathrm{~s}$, $60+60 \mathrm{~s}, 120 \mathrm{~s}$, and $180 \mathrm{~s}$ ) on feldspathic porcelain and 2 adhesive systems on shear bond strengths to resin composite. It was concluded that adequate bond strength of porcelain to resin can be produced by HF etching for $120 \mathrm{~s}$. The result of this study showed that there is no significant difference in $\mu \mathrm{SBS}$ between $5 \%$ and $10 \% \mathrm{HF}$ and 20,60 and $120 \mathrm{~s}$ etching times. In this study, $\mu$ SBS of e.max was significantly higher than Vita Mark II, it is because of significant higher fracture resistance of e.max CAD than Vita Mark II ((1378 N/1025 N) versus (405 N/454 N) (p $<.05)(26)$. IPS-e.max CAD has up to 70 vol. \% crystalline content in glassy matrix. It is composed of $58 \%$ silica ( $\mathrm{SiO} 2)$, lithium-metasilicate, -disilicate and -phosphate crystals and $10 \%$ zirconia crystals. Crystallization of e.max is a two-stage process. Primarily, the lithium metasilicate crystals accelerate ( $40 \mathrm{vol} \%$ of $0.2-1.0 \mathrm{~mm}$ crystal size). Eventually, heating under vacuum culminates in the development of a more advanced crystalline content with finer lithium-disilicate crystals (70 vol. \% of $1.5 \mathrm{~mm}$ grain size) which are incorporated into a glassy matrix. Development of highly interlocked microstructure during final crystallization, results in increased strength of e.max. Vita Mark II is a ceramic material without zirconium, and composed of a weak glass matrix phase and one or more irregularly-shaped crystalline phases, which are more brittle and weaker than zirconia. That is why its fracture strength is lower than e.max (27). Zogheib and Della Bonna (17) stated that the flexural strength of the lithium disilicate-based glass ceramic decreased after HF etching. The reason for this could be explained by the amounts of the glass phase involving lithium disilicate crystals. Several studies examined different ceramics, and the weakening effect of HF etching was confirmed $(25,28,29)$. So, by increasing the etching time and HF concentration, disruption of surface increases and it may lead to cohesive or mixed failure more than adhesive. As it has been seen in this study, in e.max groups, in 5\% concentration, adhesive failure was more than others, and in $10 \%$ concentration, mixed failure was dominant. By increasing HF concentration, the failures turn from adhesive to mixed failure. Adhesive failure means that the strength of the adherend is more than the adhesive, cohesive failure means that the adherend's strength is lower than the adhesive and mixed failure shows that the strength of the adherend and the adhesive is equal. So, by increasing etching time and HF concentration, mixed and cohesive failures might increase comparing to adhesive failure. Our study limitation was the use of a sectioning machine for making of beams, because sectioning stress could decrease real $\mu$ SBS.

\section{Conclusions}

The results showed that in both e.max and Vita Mark II groups, $\mu$ SBS were not significantly different when different etching times and HF acid concentrations were used, but the highest $\mu$ SBS was shown in Ea60 and Mb20 groups. The $\mu$ SBS of e.max was significantly higher than Vita Mark II. For clinical use, we suggest that in both e.max and Vita Mark II ceramic restorations, $20 \mathrm{~s}$ etching with $5 \%$ HF is sufficient to have acceptable bond strength without weakening of ceramics. Further studies could be performed on the effect of HF surface treatments on the bond strength of other CAD/CAM ceramics such as Vita Suprinity and Vita Enamic to resin cement.

\section{Acknowledgments:}

We would like to thank Dental Materials Research Center and Research Council of Babol University of Medical Sciences. This study was based on a postgraduate by Faraneh Mokhtarpour supervised by Homayoon Alaghehmand at the dental school of Babol University of Medical Sciences. The grant number of this research project is 9440514 . 


\section{Conflict of Interest:}

There is no conflict of interest to be declared.

\section{Authors' contributions:}

All authors contributed to this project and article equally. All authors read and approved the final manuscript.

\section{References:}

1) Xiaoping L, Dongfeng R, Silikas N. Effect of etching time and resin bond on the flexural strength of IPS e.max Press glass ceramic. Dent Mater. 2014; 30(12): e330-e6. doi: 10.1016/j.dental.2014.08.373. PMID: 25189110.

2) Miyazaki $T$, Nakamura $T$, Matsumura $H$, Ban $S$, Kobayashi T. Current status of zirconia restoration. J Prosthodont Res. 2013; 57(4): 236-61. doi: 10.1016/j.jpor.2013.09.001. PMID: 24140561.

3) Li RW, Chow TW, Matinlinna JP. Ceramic dental biomaterials and CAD/CAM technology: State of the art. J Prosthodont Res. 2014; 58(4): 208-16. doi: 10.1016/j.jpor.2014.07.003. PMID: 25172234.

4) Powers JM, Farah JW, O'Keefe KL, Kolb B, Udrys G. Guide to all-ceramic bonding. Dental Advisor. 2009; 2: 1-12.

5) Liu PR, Essig ME. Panorama of dental CAD/CAM restorative systems. Compend Contin Educ Dent. 2008; 29(8): 482-8. PMID: 18935787.

6) Fasbinder DJ, Dennison JB, Heys D, Nevia G. A clinical evaluation of chairside lithium disilicate CAD/CAM crowns. J Am Dent Assoc. 2010; 141: 10S-4S. doi: 10.14219/jada.archive.2010.0355. PMID: 20516109.

7) Kon M, Kawano F, Asaoka K, Matsumoto N. Effect of leucite crystals on the strength of glassy porcelain. Dent Mater. 1994; 13(2): 138-47. doi: 10.4012/dmj.13.138. PMID: 7758273.

8) Seghi RR, Sorensen JA. Relative flexural strength of six new ceramic materials. Int J Prosthodont. 1995; 8(3): 239-46. PMID: 10348592.

9) Seghi RR, Denry IL, Rosenstiel SF. Relative fracture toughness and hardness of new dental ceramics. J Prosthet Dent. 1995; 74(2): 45-50. doi: 10.1016/S0022-3913(05)80177-5. PMID: 8537920.

10) Denry IL, Mackert Jr. JR, Holloway JA, Rosenstiel SF. Effect of cubic leucite stabilization on the flexural strength of feldspathic dental porcelain. J Dent Res. 1996; 75(12): 1928-35. doi: 10.1177/00220345960750120301. PMID: 9033446.

11) Özcan M, Vallittu PK. Effect of surface conditioning methods on the bond strength of luting cement to ceramics. Dent Mater. 2003; 19(8): 725-31. doi: 10.1016/S0109-5641(03)00019-8. PMID: 14511730.

12) Peumans M, Van Meerbeek B, Lambrechts $P$, Vanherle G. Porcelain veneers: a review of the literature. Journal of dentistry. 2000; 28(3): 163-77. doi: 10.1016/S0300-5712(99)00066-4. PMID: 10709338.

13) Van Noort R, Barbour ME. Introduction to Dental Materials. 4th Edition. Introduction to Dental Materials. Elsevier Health Sciences; 2013.

14) Stangel I, Nathanson D, Hsu CS. Shear strength of the composite bond to etched porcelain. J Dent Res. 1987; 66(9): 1460-5. doi: 10.1177/00220345870660091001. PMID: 3305639.

15) Addison O, Marquis PM, Fleming GJ. The impact of hydrofluoric acid surface treatments on the performance of a porcelain laminate restorative material. Dent Mater. 2007; 23(4): 461-8. doi: 10.1016/j.dental.2006.03.002.

16) Chen JH, Matsumura H, Atsuta M. Effect of etchant, etching period, and silane priming on bond strength to porcelain of composite resin. Oper Dent. 1998; 23: 250-7. PMID: 9863446.

17) Zogheib LV, Della Bona A. Effect of hydrofluoric acid etching duration on the roughness and flexural strength of a lithium disilicate-based glass ceramic. Braz Dent J. 2001; 22(1): 45-50. doi: 10.1590/S010364402011000100008. PMID: 21519648.

18) Chen JH, Matsumura H, Atsuta M. Effect of different etching periods on the bond strength of a composite resin to a machinable porcelain. J Dent. 1998; 26(1): 53-8. doi: 10.1016/S0300-5712(96)00078-4.

19) Jardel V, Degrange M, Picard B, Derrien G. Surface energy of etched ceramic. Int J Prosthodont. 1999; 12(5): 415-8. PMID: 10709522.

20) Lu R, Harcourt JK, Tyas MJ, Alexander B. An investigation of the composite resin/porcelain interface. Aust Dent J. 1992; 37: 12-9. doi: 10.1111/j.1834-7819.1992.tb00827.x. PMID: 1567289.

21) Nagayassu MP, Shintome LK, Uemura ES, Araujo JE. Effect of Surface Treatment on the Shear Bond Strength of a Resin-Based Cement to Porcelain. Braz Dent J. 2006; 17(4): 290-5. doi: 10.1590/S010364402006000400005. PMID: 17262141. 
22) Tylka DF, Stewart GP. Comparison of acidulated phosphate fluoride gel and hydrofluoric acid etchants for porcelain-composite repair. J Prosthet Dent. 1994; 72(2): 121-7. doi: 10.1016/0022-3913(94)90067-1. PMID: 7932255.

23) Shimada Y, Yamaguchi S, Tagami J. Micro-shear bond strength of dual-cured resin cement to glass ceramics. Dent Mater. 2002; 18(5): 380-8. doi: 10.1016/S0109-5641(01)00054-9. PMID: 12175577.

24) Güler AU, Yilmaz F, Yenisey M, Güler E, Ural Ç. Effect of acid etching time and a self-etching adhesive on the shear bond strength of composite resin to porcelain. J Adhes Dent. 2006; 8(1): 21-5. PMID: 16536340.

25) Della Bona A, Anusavice KJ, Hood JA. Effect of ceramic surface treatment on tensile bond strength to a resin cement. Int J Prosthodont. 2002; 15(3): 248-55. PMID: 12066487.

26) Stona D, Burnett LH, Mota EG, Spohr AM. Fracture resistance of computer-aided design and computeraided manufacturing ceramic crowns cemented on solid abutments. J Am Dent Assoc. 2015; 146(7): 501-7. doi: 10.1016/j.adaj.2015.02.012. PMID: 26113098.

27) Badawy R, El-Mowafy O, Tam LE. Fracture toughness of chairside CAD/CAM materials-Alternative loading approach for compact tension test. Dent Mater. 2016. doi: 10.1016/j.dental.2016.03.003. PMID: 27133875.

28) Wolf DM, Powers JM, O'Keefe KL. Bond strength of composite to etched and sandblasted porcelain. Am J Dent. 1993; 6(3): 155-8. PMID: 8240779.

29) Hooshmand T, Parvizi S, Keshvad A. Effect of surface acid etching on the biaxial flexural strength of two hot-pressed glass ceramics. J Prosthodont. 2008; 17(5): 415-9. doi: 10.1111/j.1532-849X.2008.00319.x. PMID: 18482364.

30) Subasi G, Inan O. Shear Bond Strength of Three Porcelain Repair Systems on Porcelain in Dry and Aged Conditions. Dentistry 2012; 2: 119-25. doi: 10.4172/2161-1122.1000119.

31) Chaiyabutr Y, McGowan S, Phillips KM, Kois JC, Giordano RA. The effect of hydrofluoric acid surface treatment and bond strength of a zirconia veneering ceramic. J Prosthet Dent. 2008; 100(3): 194-202. doi: 10.1016/S0022-3913(08)60178-X. PMID: 18762031. 